\title{
Effect of the intermediate quenching on fracture toughness of ferrite- martensite dual phase steels
}

\author{
B. Sunil \\ Department of Mechanical Engineering, Siddaganga Institute of Technology, Tumakuru, VTU-Belagavi, India \\ sunilb@sit.ac.in \\ S. Rajanna \\ Department of Mechanical Engineering, Government Engineering College, Kushalnagar, VTU-Belagavi, India \\ rajanna.cit@gmail.com
}

\begin{abstract}
The main aim of the research work is to examine the fracture toughness of the dual phase steels prepared using the intermediate quenching method. The ferrite-martensite dual phase (DP) steel is produced using low carbon micro alloyed steel by the heat treatment and intercritical quenching technique using various intercritical temperatures such as 740,760,780,800 and $820 \mathrm{oC}$. The samples of the produced dual phase steel are analyzed for their microstructure using optical microscope. The fracture toughness investigations for the dual phase steel have been carried out using ASTM standard testing procedure. From the results it is observed that the fine distribution and equal volume fraction of ferrite and martensite phases at $780 \circ$ C. The effect of which, the A780 steel has demonstrated excellent fracture toughness which is the result of intermediate quenching technique. The fractography analysis it is clear that the ductile initiated brittle fracture is occurred which is due to the increased hard martensite phase and the increment in the stress accumulation at the ferrite which also leads to the higher elongation.
\end{abstract}

KEYWORDS. Martensite; Ferrite; Intercritical temperature; Volume fraction; Dual phase steel; Fracture toughness.

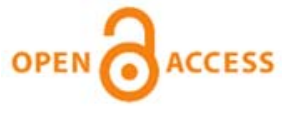

Citation: Sunil, B., Rajanna, S., Thermal Effect of the intermediate quenching on fracture toughness of ferrite-martensite dual phase steels, Frattura ed Integrità Strutturale, 55 (2021) 271-277.

Received: 03.12.2020

Accepted: 18.12 .2020

Published: 01.01.2021

Copyright: (C) 2021 This is an open access article under the terms of the CC-BY 4.0, which permits unrestricted use, distribution, and reproduction in any medium, provided the original author and source are credited.

\section{INTRODUCTION}

$\mathrm{T}$ he steel grades of properties such as high strength, strong, safe, economic and reliable are used as the steel structures for automobile, aerospace components. From last two decades many researchers have developed many grades of steel such as high strength steels (HSS) [1] to fulfill the demands of the automobile industries on safety and reduced weight. The high strength steels are the new interested and exploring area for research for many of the researchers for its advanced capabilities. Because of cost effectiveness and light weight of HSS, these are used for the manufacture of automobile body and chassis. Hence, extensive research has to be carried out to develop its optimized microstructure for improved structural integrity and mechanical performance. By utilizing the suitable characterization methods, it is possible to optimize and comprehend the micro-structural constituents on the fracture behavior and its performance. The limited 
ductility of high strength steel in contrast with the mild steel has increased the cracking issues were not possible to characterize using the conventional uniaxial tensile test experimentation.

In this perspective, fracture mechanics based evaluation of the HSS will give the more understanding of the fracture behavior of the material related the crack initiation and resistance to crack propagation [2]. From the works of Yoon et al. [2] and Casellas et al. [3] worked on the high strength steel sheets and observed that the correlation between the edge crack resistance and fracture toughness of the material. The same methodology has been further investigated for the edge formability of dual phase and complex phase steel [4-5] for their resistance to crack propagation. Such high strength steel, which is fulfill the requirements of increased ductility, high initial strain hardening rate, high strength with high formability attributes [6] is the dual phase (DP) steel. DP steel suits the strength and ductility requirements as its phases consists of ferrite and martensite. Research also shows, dual phase steels are considered as metallic composite due to its composite microstructure, have the special characteristics like high strength and ductility properties, excellent formability [7], light weight [8-9], continuous yielding behavior, uniform plastic deformation, better work hardenability, ease of welding [10-11]. With these properties, dual phase steels are considered to be attractive and potential material for the use in automobile and structural industries.

Dual phase steels are produced, in a simple and easy way, by the intercritical heat treatment method also referred as intermediate quenching (IQ) method [12-13] from the Low carbon micro alloy steels. The low carbon micro alloyed steels were heated to the austenization temperature followed by the rapid quenching where it forms the martensite phase. The quenched samples were further intercritically annealed [14] for the shorter period and quenched to obtain the required volume fraction of the ferrite-martensite phases. Rajanna $S$ et al [15-18] studied the microstructure and mechanical properties of the rail steel. Sunil B et al [19] studied the effect of carbon on the microstructure of the DP steels. From results obtained it is clear that the as martensite content increases hardness of the DP steels.

Jiecen Zhang et al [21] studied two different morphologies of martensite in DP steels viz., intermediate quenching (IQ) and cold rolled intercritical annealing (CR-IA). For both the cases inter-critical temperature varied from $750 \mathrm{oC}$ to $850 \mathrm{oC}$ to obtain the different martensite volume fraction. From the results it is observed that, in both samples, with the increment in the inter-critical temperature, the existing fibrous martensite is converted into blocky martensite eventually increasing the martensite cracking. On the other hand, there is decrement in the martensite cracking was observed in the IQ samples with the increment in the martensite fraction.

The investigations on different advanced high strength steels such as complex phase steel, dual phase steel, trip-aided bainitic ferritic steel and quenching and partitioning steel [22] was carried out to access the crack initiation and propagation resistance by means of different assessments. Among the different parameters adopted, specimen geometry, testing method were found independent parameters which doesn't affect the crack initiation resistance.

Shengci $\mathrm{Li}$ et al [23] used the compact tension (CT) specimen to evaluate the fracture behavior of the DP780 dual phase steel. Also the effect of loading [24], elevated temperature [25], inclusions [26], ferrite morphology and of ferrite volume fraction [27] of the ferritic/martensitic stainless steel was studied by the various authors. From the results it is recommended that the volume fraction of the produced ferrite/martensite influence the fracture toughness of the material. The fracture toughness testing using CT specimens is the most widely used one [28]. The fracture toughness of as-cast and annealed medium carbon steel was investigated using the round notched tensile specimen for different notch diameters and angles [29] and found that higher notch angle and lower notch diameter demonstrate higher value of fracture toughness. Fracture toughness of medium carbon steel using circumferential notched tensile (CNT) specimens [30] was carried out and found that the results obtained were in close relation with the literature [29].

In the present work, the main aim is to brief review on the fracture toughness of the dual phase steel produced through intermediate quenching (IQ) [31] technique. The motivation to use the IQ samples is that, as the martensite fraction increases the martensite cracking decreases [21] in the dual phase steels. It is aimed to provide the better understanding of the fracture behavior of the DP steels, as the literature survey shows the few authors worked on the fracture characterization. For the same, the advanced high strength steel like dual phase steel, which commonly used in the automobile sectors, is used to investigate the fracture toughness using the LEFM based techniques.

\section{MATERIAL AND PREPARATION}

he material used in the present work is the hot rolled low carbon micro alloyed steel plate of $8 \mathrm{~mm}$ thick. In its chemical composition, it observed that the major alloying elements are Ni- $0.4 \%, \mathrm{Mn}-1.32 \%, \mathrm{C}-0.16 \%, \mathrm{Si}-0.42 \%$ [31]. The some of the minor elements include S, P, Mo, V, B and Cr, which are also influence the performance of the DP steel. The concentration of the alloying elements was measured by utilizing the optical emission spectrometer. 
The intercritical heat treatment process has been carried out in a laboratory thermocouple controlled muffle furnace. The lower critical $\left(\mathrm{AC}_{1}\right)$ and upper critical $\left(\mathrm{AC}_{3}\right)$ temperatures [31] were determined. The heat treatment procedure followed is as mentioned by the Sunil B et al [31].

\section{EXPERIMENTATION}

$\mathrm{F}$ rom the prepared DP steels, samples are machined to the requisite thickness and width to fulfill the plain strain condition. The prepared samples of the DP steel are machined to the requisite dimensions as per the American society for testing and materials (ASTM) standard [20]. The specimen used for the fracture toughness testing is, the compact tension (CT) specimen, as per ASTM E399 standard as shown in Fig.1. The requisite specimens have a notch of size $2 \mathrm{~mm} \times 12 \mathrm{~mm}$ and were prepared using wire-cut EDM at an accuracy of $0.1 \mathrm{~mm}$. In the servo hydraulic testing machine, the fatigue crack of $1 \mathrm{~mm}$ is introduced for the crack length to width $(\mathrm{a} / \mathrm{W})$ ratio of 0.45 , at the end of the notch. The displacement rate of $1 \mathrm{~mm} / \mathrm{min}$ is maintained [28] in the conducted fracture toughness tests. The specimens tested were subjected to load ratio of 0.1 and cyclic load at the frequency $5 \mathrm{~Hz}$. All the CT specimens of DP steels of thickness $(\mathrm{B})=$ $6 \mathrm{~mm}$ are tested to find the fracture toughness using a universal testing machine (UTM) as per ASTM standard testing procedure.

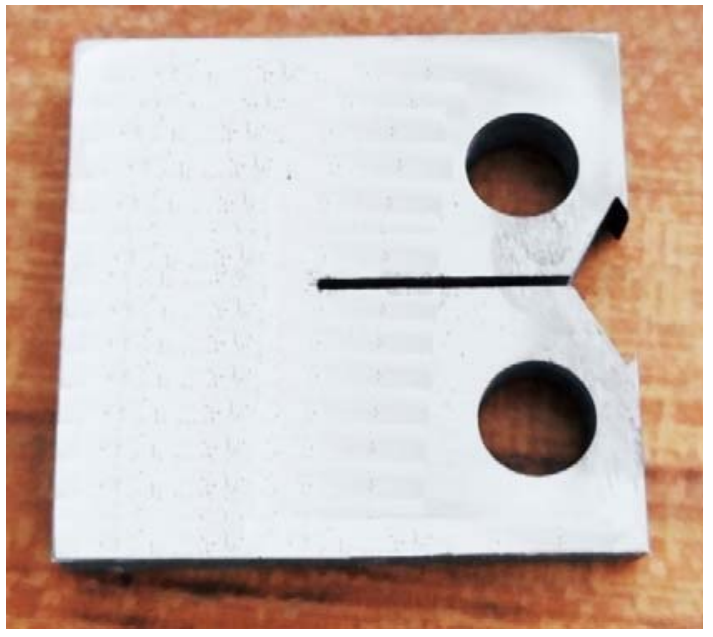

Figure 1 (a): CT Specimen with $780^{\circ} \mathrm{C} \mathrm{IQ}$ temperature

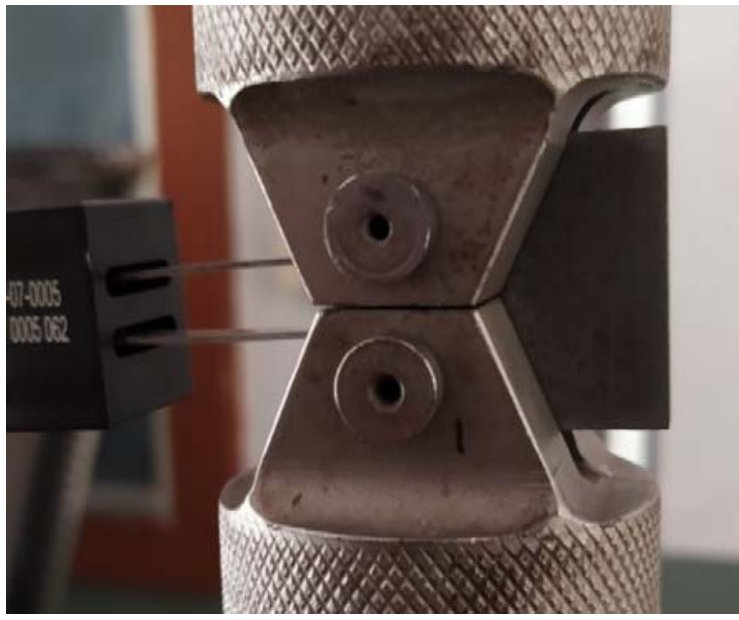

Figure 1 (b): experimental setup

For the each specimen tested, the value of the critical load PQ and the crack opening displacement is measured and using those values the fracture toughness $\left(\mathrm{K}_{\mathrm{Ic}}\right)$ is determined using the empirical equation available in the literatures [20, 26].

\section{RESULTS AND DISCUSSION}

1 he fracture load and the calculated value of the fracture toughness of all the specimens of dual phase steel for the different IQ temperatures have been listed in the Tab. 1. From the table, it can be observed that the increment in the IQ temperatures leads to increment in the fracture toughness up to the 780oC. Later, the decrement in the values of the fracture toughness is observed. The increment and decrement in the fracture toughness of the dual phase steel is mainly due to the volume fraction of the ferrite-martensite phase formed during the processing.

It is seen that the DP steel developed from hot rolled low carbon micro alloyed steel exhibits better fracture toughness values in comparison with the dual phase steels produced with medium carbon steel [30]. The fracture toughness of the A780 steel is yielding the maximum fracture toughness i.e. KIc of $54.89 \mathrm{MPa} \sqrt{\mathrm{m}}$ with DP800 yielded a fracture toughness of $52.70 \mathrm{MPa} \sqrt{\mathrm{m}}$ (reduction of $4 \%$ in contrast with the A780). The A820 yielded the lesser fracture toughness of 49.10 $\mathrm{MPa} \sqrt{\mathrm{m}}$ (a further reduction of 10\% in contrast with the A780). This further decrement in the fracture toughness with the A820 specimen is a result of the high volume fraction of martensite $(60 \%)$. 
The Fig 2 shows the variation of the fracture toughness of the dual phase steel with the increment in the intermediate quenching temperature. From the fig it is observed that as the increment in IQ temperature leads to increase in the fracture toughness up to the $780 \mathrm{oC}$, later fracture toughness decreases. The increased fracture toughness of A780 is characterized by the hard martensite and soft ferrite phase, which assist in the increment in the material resistance to crack initiation and propagation. From the literature [29-30], the fracture toughness of the above said materials is in close agreement with the DP steels produced from medium carbon steels using the similar intercritical temperatures. The dual phase steel prepared by the intermediate quenching method maintains the appreciable ductility and thus gives the better resistance to the crack propagation. The facture toughness test was conducted using the CNT [29] and CT specimens are in good agreement with each other. However, the steep stress induced by the notch, the fracture toughness values obtained from the CNT specimens is lower than the CT specimens.

\begin{tabular}{cccccc}
\hline Specimen & $\begin{array}{c}\text { Thickness (B) } \\
\mathrm{mm}\end{array}$ & $\begin{array}{c}\text { Width } \\
(\mathrm{W}) \mathrm{mm}\end{array}$ & $\begin{array}{c}\text { Fracture Load } \\
(\mathrm{PQ}) \mathrm{kN}\end{array}$ & $\mathrm{f}(\mathrm{a} / \mathrm{W})$ & $\begin{array}{c}\mathrm{K}_{\mathrm{lc}} \\
\mathrm{MPa} \sqrt{\mathrm{m}}\end{array}$ \\
$\mathrm{A} 740$ & 08 & 40 & 8.79 & 8.34 & 45.82 \\
$\mathrm{~A} 760$ & 08 & 40 & 9.48 & 8.34 & 49.41 \\
$\mathrm{~A} 780$ & 08 & 40 & 10.53 & 8.34 & 54.89 \\
$\mathrm{~A} 800$ & 08 & 40 & 10.11 & 8.34 & 52.70 \\
$\mathrm{~A} 820$ & 08 & 40 & 9.42 & 8.34 & 49.10 \\
\hline
\end{tabular}

Table 1: KIc of dual phase steel at different IQ temepratures

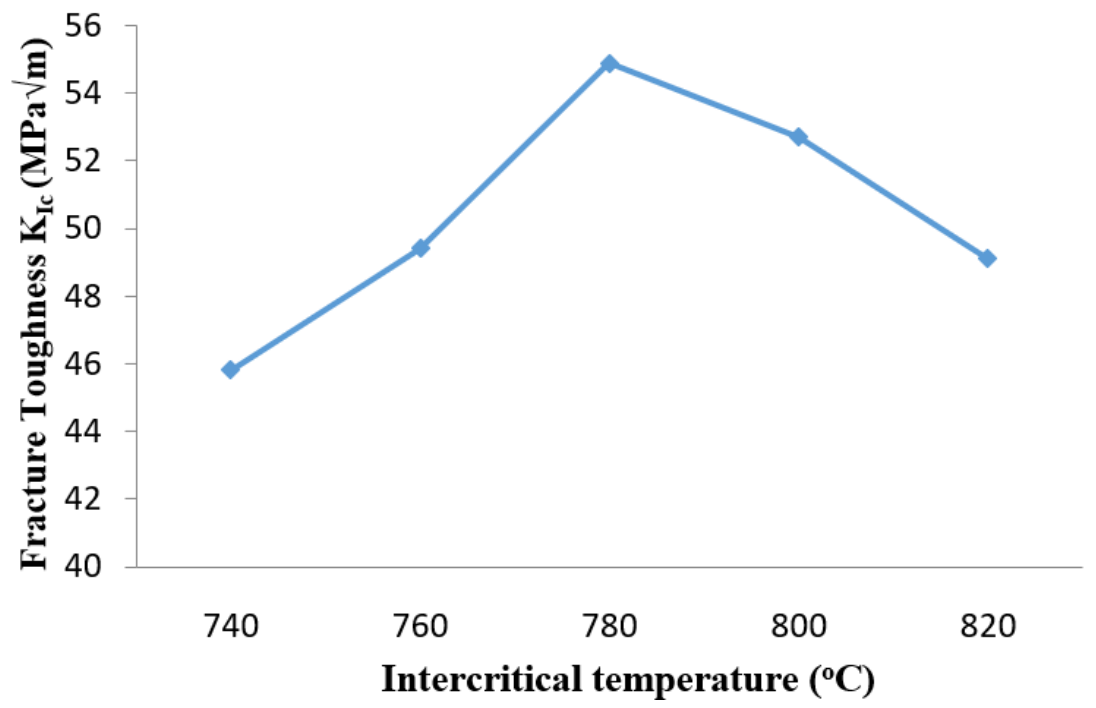

Figure 2: Variation of fracture toughness with respect to IQ temperature

In the Fig 3, the fractography of the tested samples shows both ductile and brittle fracture. The DP steels produced using the intermediate quenching technique at 740,760 and $780^{\circ} \mathrm{C}$ shows the ductile fracture under the tensile loading whereas the DP steels at 800 and $820^{\circ} \mathrm{C}$ shows the ductile initiated brittle fracture. The increment in the fracture toughness up to the $780^{\circ} \mathrm{C}$, is the sign of increasing the hard martensite phase and availability of soft ferrite phase. Due to which the ductile fracture has occurred. The ductile initiated brittle fracture is due to the increased hard martensite phase and the increment in the stress accumulation at the ferrite. Since there is no sign of sudden transition of ductile to brittle in the fractographs, there is a higher percentage of elongation. 


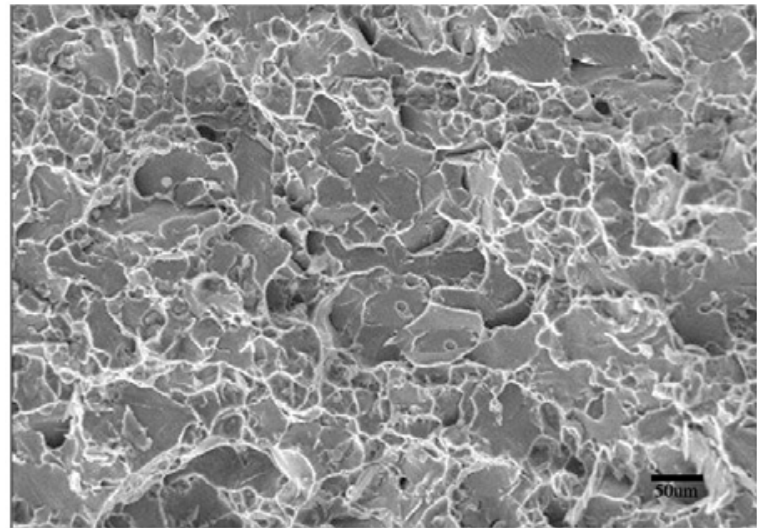

(a) A740

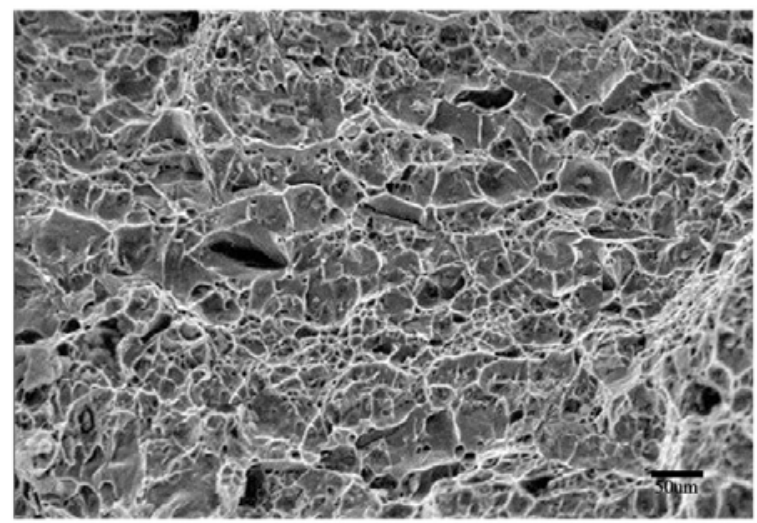

(c) A780

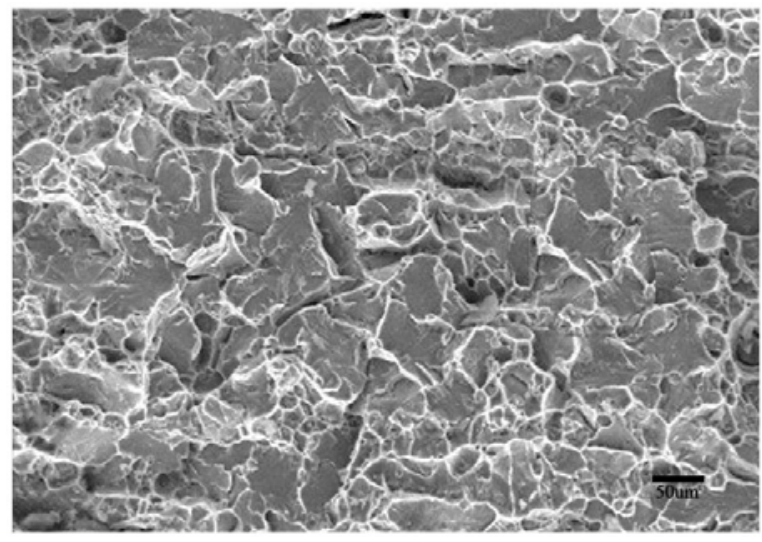

(b) A760

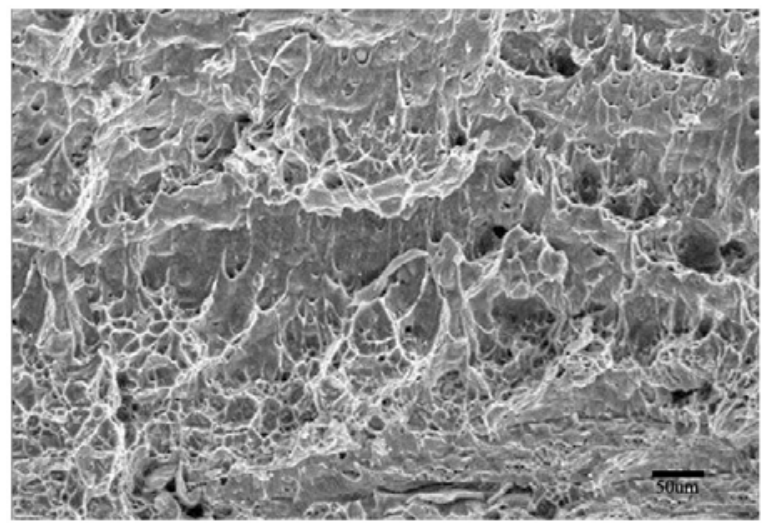

(d) A800

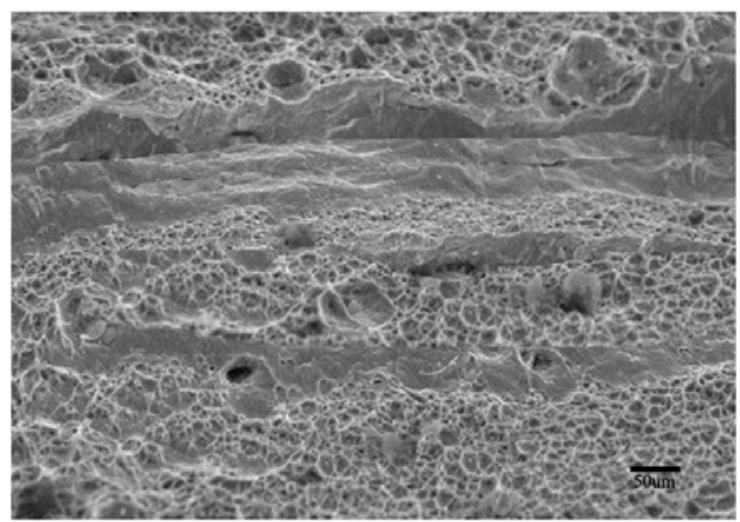

(e) A820

Figure 3: Microstructure of fractured surfaces for DP steels

\section{CONCLUSIONS}

7 he low carbon micro alloyed steel is used to prepare the dual phase steels and fracture toughness of the same has been evaluated. From the outcomes of the experiments following conclusions were drawn.

I. Dual phase steels can be produced successfully from the hot rolled low carbon micro alloy by using the intermediate quenching techniques which forms the different volume fractions of the ferrite-martensite phases. 
II. The obtained equal volume fraction and fine distribution of ferrite and martensite phases, exhibits the better fracture toughness. The equal volume fraction of the ferrite-martensite phases helps to maintain the appreciable ductility and thus gives the greater resistance to crack initiation and propagation.

III. From the comparison of CT specimens and CNT specimens (from literatures), it is clear that, the geometry of the specimens will not affect majorly on the fracture toughness of the material. However the fracture toughness of the DP steels produced from low carbon micro alloy steels exhibits better results as compared to the DP steels produced from the medium carbon steels.

IV. From the fractography tests it is clear that the ductile initiated brittle fracture is observed which is due to the increased hard martensite phase and the increment in the stress accumulation at the ferrite which also leads to the higher elongation.

\section{FUNDING}

his research received no specific grant from any funding agency in the public, commercial, or not-for-profit sectors.

\section{CONFLICT OF INTEREST}

he authors declare that they have no conflict of interest.

\section{REFERENCES}

[1] Movaheda, P., Kolahgara, S., Marashia, S.P.H., Pouranvari, M, Parvin, N. (2009). The effect of intercritical heat treatment temperature on the tensile properties and work hardening behavior of ferrite-martensite dual phase steel sheets. Materials Science and Engineering A 518, pp. 1-6. DOI: 10.1016/j.msea.2009.05.046

[2] Yoon, J.I., Jung, J., Joo, S.H., Song, T.J., Chin, K.G., Seo, M.H. (2016). Correlation between fracture toughness and stretch-flangeability of advanced high strength steels. Matter Lett, 180, pp. 322-326.

[3] Casellas, D., Lara, A., Frómeta, D., Gutiérrez, D., Molas, S., Pérez, Ll. (2017). Fracture toughness to understand stretchflangeability and edge cracking resistance in AHSS. Metall Mat Trans A, 48, pp.86-94.

[4] Frómeta, D., Tedesco, M., Calvo, J., Lara, A., Molas, S., Casellas, D., (2017). Assessing edge cracking resistance in AHSS automotive parts by the Essential Work of Fracture methodology. J Phys: Conf Ser, 896, 012102.

[5] Frómeta, D., Lara, A., Parareda, S., Casellas, D. (2019). Evaluation of edge formability in high strength sheets through a fracture mechanics approach. AIP Conf Proc 2113, 160007.

[6] Debdulal, D., Partha Protim, C., (2009). Influence of martensite morphology on the work-hardening behavior of high strength ferrite-martensite dual-phase steel. J Mater Sci 44, pp. 2957-2965. DOI:10.1007/s10853-009-3392-0.

[7] Saaia, O.S., Hopperstad, Y., Granbomc, O.-G. (2014). Influence of volume fraction and distribution of martensite phase on the strain localization in dual phase steels. Procedia Materials Science, 3, pp. $900-905$.

[8] Ahmad, E., Manzoor, T., Ziai, M.M.A., Hussain, N. (2012). Effect of Martensite Morphology on Tensile Deformation of Dual-Phase Steel. Journal of Materials Engineering and Performance 21, pp. 382-387.

[9] Adamczyk, J., Grajcar, A. (2007). Heat treatment and mechanical properties of low-carbon steel with dual-phase microstructure. Journal of Achievements in Materials and Manufacturing Engineering 22.1.

[10] Rajanna, S., Shivanand, H.K., Akash Deep, B.N. (2009). Improvement in mechanical behaviour of expulsion with heat treated thermite welded rail steel. Proc. Of World Academy of science, Engineering and Technology. 60, pp. 558-562.

[11] Poole, M., Mazinani, W.J. (2007). Effect of Martensite Plasticity on the Deformation Behavior of a Low-Carbon DualPhase Steel. Metallurgical And Materials Transactions A, pp. 328-339. 
[12] Sharma, P. (2017). Study of the Effect of Quenched and Inter Critical Heat Treatment on Mechanical Properties of Plain Low Carbon Steel (0.09\% C, 0.5\% Mn, 0.05\% S). International Journal of Current Engineering and Technology 7(1), pp. $2347-5161$.

[13] Rudnizki, J., Prahl, U. and Bleck, W. (2012). Phase-field modelling of microstructure evolution during processing of cold-rolled dual phase steels. Integrating Materials and Manufacturing Innovation, pp-1-3.

DOI: $10.1186 / 2193-9772-1-3$

[14] Bello, K.A., Hassan S.B. and Aponbiede, O. (2011). Effects of Austenitising Conditions on the Microstructures and Mechanical Properties of Martensitic Steel with Dual Matrix Structure. Journal of Minerals \& Materials Characterization \& Engineering 11(1), pp. 69-83. DOI: 10.4236/jmmce.2012.111006

[15] Rajanna, S., Shivanand, H.K., Deep, B.N. (2009). Improvement in mechanical behavior of expulsion with heat treated thermite welded rail steel, Proceedings of World Academy of Science, Engineering and Technology, 60, pp. 558-562.

[16] Rajanna, S. and Shivanand, H.K. (2009). Improvement in mechanical response of thermite welded rail steel using expulsion with heat treatment, International Journal of Materials Science, 4(3), pp. 313-322.

[17] Shantharaja, M., Rajanna, S., Shivanand, H.K. and Keshavamurthy, Y.C. (2009). Characterization of mechanical properties of postweld heat-treated shielded manual metallic arc welded rails, International Journal of Recent Trends in Engineering, 1(5), 153.

[18] Rajanna, S. and Shivanand, H.K. (2008). Microstructure and mechanical characterization of post weld heat treated thermite welded rails, Indian Welding Journal, 41(1), 44.

[19] Sunil, B., Rajanna, S. (2018). Influence of Carbon Percentage on the microstructure of Dual Phase steel, International Journal of Advanced Research Methodology in Engineering \& Technology, 2(1), pp.108-112.

[20] ASTM Standards (2017). Standard Test Method for Plane-Strain Fracture Toughness of Metallic Materials, ASTM International, E 399-17.

[21] Jiecen, Z., Hongshuang, D., Yonggang, D., Misra, R.D.K. (2015). Effect of martensite morphology and volume fraction on strain hardening and fracture behavior of martensite-ferrite dual phase steel. Materials Science \& Engineering A, 627, pp. 230-240. DOI: 10.1016/j.msea.2015.01.006.

[22] Frómeta, D., Parareda, S., Lara, A., Molas, S., Casellas, D., Jonsén, P., Calvo, J. (2020). Identification of fracture toughness parameters to understand the fracture resistance of advanced high strength sheet steels. Engineering Fracture Mechanics, 229, 106949. DOI: 10.1016/j.engfracmech.2020.106949.

[23] Shengci, L., Yinghui, Z., Liang, Q., Yonglin, K. (2018). Effect of single tensile overload on fatigue crack growth behavior in DP780 dual phase steel, International Journal of Fatigue, 106, pp. 49-55. DOI: 10.1016/j.ijfatigue.2017.09.018.

[24] Huaxin, L., Jones, R.H., Hirth, J.P., Gelles, D.S. (1994). Effect of loading mode on the fracture toughness of a reducedactivation ferritic/martensitic stainless steel, Journal of Nuclear Materials, 212-215, pp. 741-745.

[25] Dubey, J.S., Wadekar, S.L., Chakravartty, J.K. (1998). Elevated temperature fracture toughness of AISI 403 martensitic stainless steel, Journal of Nuclear Materials, 254, pp. 271-274.

[26] Pouranvari, M. (2017). Fracture toughness of martensitic stainless steel resistance spot welds, Materials Science \& Engineering A, 680, pp. 97-107. DOI: 10.1016/j.msea.2016.10.088.

[27] Ulu, S., Aytekin, H., Said, G. (2013). An alternative approach to the fracture toughness of dual phase steels, Strength of Materials, 45(5). DOI: 10.1007/s11223-013-9498-2.

[28] Doddamani, S. and Kaleemulla, M. (2018). Effect of graphite on fracture toughness of 6061 Al-Graphite, Strength, Fracture and Complexity, 11(4), pp 295-308. DOI:10.3233/SFC-180230.

[29] Nath, S. K. and Kr Das, U. (2006). Effect of Microstructure and Notches on the Fracture Toughness of Medium Carbon Steel, Journal of Naval Architecture and Marine Engineering, 3, pp 15-22.

[30] Kanayo Alaneme, K. (2011). Fracture Toughness (K1C) Evaluation for Dual Phase Medium Carbon Low Alloy Steels Using Circumferential Notched Tensile (CNT) Specimens, Materials Research, 14(2), pp. 155-160.

[31] Sunil, B., Rajanna, S. (2020). Evaluation of mechanical properties of ferrite-martensite DP steels produced through intermediate quenching technique. SN Appl. Sci. 2, 1461. DOI: 10.1007/s42452-020-03246-4. 